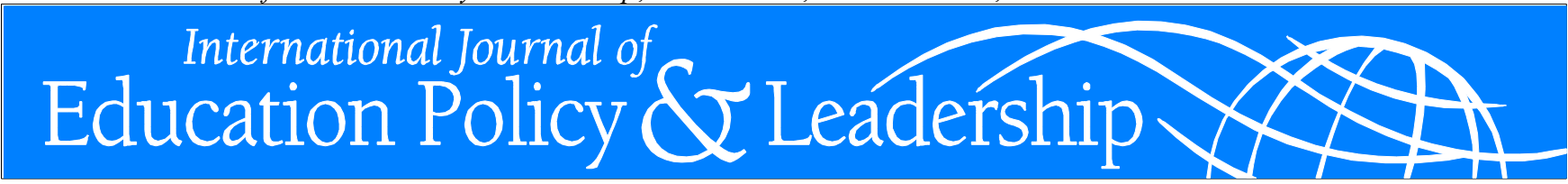

\title{
FACTORS THAT PROMOTE PROGRESSION IN SCHOOLS FunCTIONING AS PROFES- SIONAL LEARNING COMMUNITY
}

\author{
MARTINE LECLERC \\ Université du Québec en Outaouais \\ ANDRÉ C. MOREAU \\ Université du Québec en Outaouais \\ CATHERINE DUMOUCHEL \\ Université du Québec en Outaouais \\ FRANÇOIS SALLAFRANQUE-ST-LOUIS \\ Université du Québec en Outaouais
}

\begin{abstract}
The purpose of this research is to identify factors that influence the functioning of a school working as a Professional Learning Community (PLC) and to analyze the links between these factors and the school's progression. This research was developed within the context of an interpretative research paradigm. The primary data collection tool employed is a one-hour semistructured interview with each participant, thus allowing researchers to identify each participating school's level of development as a PLC and clarify the underlying factors that have a positive effect on this type of functioning. The interview plan, composed of themes relevant to this research project, is structured according to the Seidman model (1998). The schools were classified according to the three stages of development identified in the Professional Learning Communities Observation Grid (PLCOG) from Leclerc, Moreau and Lépine (2009a), namely the initiation, implementation, and integration stages, using the seven indicators found in the professional literature. This study suggests certain dominant factors, particularly for schools in the initiation and integration stages. Recommendations are presented to better assist school administrators in supporting their teaching staff as a PLC.
\end{abstract}

Leclerc, M., Moreau, A., Dumouchel, C., \& Sallafranque-St-Louis, F. (2012). Factors that promote Progression in Schools Functioning as Professional Learning Community. International Journal of Education Policy and Leadership 7(7). Retrieved from www.ijepl.org.

\section{Introduction}

Throughout the world, schools seek to improve the achievements of students because an education of high-quality is recognized as a crucial element for the success of people and for society. From now on, schools must develop a culture supported by the partnership of all participants, bringing the principal and the teachers together to work as colleagues while seeking to continuously learn from one another. The key question is as follows: How can we support such a method of functioning? The objectives of this re- search are to identify factors that influence the functioning of a school as a Professional Learning Community (PLC) and to analyze the links between these factors and the school's progression ${ }^{1}$.

\section{School as a Professional Learning Community}

The concept of "professional community" first appeared in the literature in the early 1990s (Cuban, 1992; McLaughlin, 1992), and originates with organizational theory literature. Over the last 15 years, the

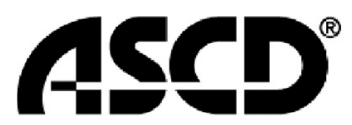

LEARN. TEACH. LEAD.
SEI SIMON FRASER UNIVERSITY THINKING OF THE WORLD

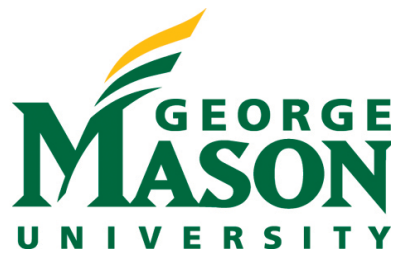


business world has understood the importance of examining workplace operations to gain a better understanding of their influence on the efficiency of the enterprise. We now accept that the knowledge gained by an individual, or a group of individuals, is an undeniable advantage in the workplace. These individuals represent the organization's most valuable resource (Wenger, 1998). Within the context of education, these processes are illustrated by a set of social relations that create a culture of shared responsibility for student learning, improve teachers' understanding of key pedagogical elements, and promote the implementation of effective practices (Louis, 2006).

Within a PLC, the relationship between teachers and other school professionals is a key element affecting student learning. This community-based environment reduces the isolation of teachers by promoting productive interactions when solving classroom difficulties. By working together, the personnel will increase their commitment to the school's goals and mission. PLCs thereby enrich their understanding of teaching and learning concepts and ensure that the varied academic disciplines are closely intertwined. Thus, the responsibility for student success becomes shared. Teachers working in this type of environment are well-informed at the pedagogical level, are committed to continuing professional development, and consider student learning as their key calling (DuFour \& Eaker, 2004; Hord, 1997; Roy \& Hord, 2006).

\section{Professional Learning Communities: Developmental Stages and Progression Indicators}

When reviewing the literature on PLCs, seven indicators clearly stand out as being crucial in evaluating the progression of a school as a PLC:

1. the school's vision

2. the physical and human conditions that encourage teachers to cooperate, learn, and share together

3. the cooperative culture of the school

4. the manifestation of leadership from both teachers and principals

5. the dissemination of expertise and shared learning

6. the topics addressed based on concerns related to student learning

7. decision making based on accurate data

(Cate, Vaughn, \& O'Hair, 2006; Dibbon, 2000; DuFour \& Eaker, 2004; Hord, 1997; Huffman \& Hipp, 2003; Leclerc et Moreau, 2009; Miller, 2005; Roy \&
Hord, 2006; Schussler, 2003; Stoll \& Temperley, 2009).

These seven indicators were used by Leclerc, Moreau and Lépine (2009a; 2009b) to analyze the progression of the school as a PLC and to identify three stages of progression. This approach allowed the development of the Observation Grid for the Progression of Schools as Professional Learning Communities $(\mathrm{PLCOG})^{2}$, summarized in the following paragraphs.

\section{Observation Grid for the Progression of Schools as Professional Learning Communities (PLCOG)}

For schools in the initiation stage (level 1), multiple priorities exist. The day-to-day operations do not reflect the vision and the priorities. Cooperation and sharing among teachers are made difficult by the human and physical conditions. There is a minimal cooperative culture, perhaps because of some interpersonal conflicts. The key decisions are made by the principal and the dissemination of expertise is limited. The team uses imprecise data to measure the effect of its interventions on student progression.

Schools in the implementation stage (level 2) have a clear and shared vision, and the relationship between the school's selected priorities and its vision are sometimes reflected in its day-to-day operations. Human and physical conditions are such that they promote collaboration and sharing among teachers. The collaborative culture is more evident because the team demonstrates several interpersonal skills that promote sharing. The principal shares a certain amount of power with the teachers, and the team occasionally uses more precise data that allows it to measure the effect of its interventions on student progression.

Schools in the integration stage (level 3) have a clear and shared vision that is evident in its pedagogical practices. Collaboration and sharing are easily encouraged by the human and physical conditions. The collaborative culture is solid and well-supported by the obvious manifestation of interpersonal skills that promote sharing and questioning. The principal shares power with teachers and encourages them to develop leadership abilities. Teachers consider collaborative meetings as a means of improving student learning as well as a powerful tool for their own professional development. Meetings are planned keeping in mind the students' profiles and the progression of the collaborative team. PLCOG explains these three developmental stages at following address: 
http://www.eera-ecer.eu/ecer-programmes-and-presen tations/conference/ecer2009/contribution/255/? no_cache $=1 \& \mathrm{cHash}=$ de $6 \mathrm{e} 2 \mathrm{~d} 7 \mathrm{c} 33$

\section{Factors Influencing the Progression of a School as a PLC}

Several factors are crucial in assisting the implementation of this type of organization, such as time allocated for meetings and training, physical resources, and technical support (Huffman, 2003; Leclerc, Moreau, \& Leclerc-Morin, 2007; Leonard \& Leonard, 2003; Wenger, 1998). It appears that the school's environment is a crucial factor that influences the implementation of a PLC. This includes the school's setting for collaboration (timetables, distribution of staff, resources) and support for professional development, clearly articulated expectations in terms of academic success, a climate of confidence among staff members, and mutual support among colleagues (Cibulka, Coursey, \& Nakayama, 2000). According to Sergiovanni (2001), developing a culture of shared values that encourages positive interpersonal relationships is the basis for a learning community. This is in line with Hopkins and Reynolds (2001), who hold that a culture of collaboration within a school promotes improved teaching and a higher degree of academic achievement in North American societies, which is in agreement with the notion of a PLC.

Leadership from the principal is also a crucial factor, as emphasized by Lieberman (1999) and as demonstrated by the conclusions reached by Leclerc, Moreau and Lépine (2009a)from their study of 64 participants, which demonstrated the roles that the principal must assume to promote working as a PLC. However, according to Leithwood and Jantzi (2000) and Leithwood, Harris, and Hopkins (2008), even though leadership from the principal is a crucial factor in all changes within a school, leadership from all teachers is equally crucial. Busher (2006) maintains that the development of social cohesion within a collaborative culture allows an asymmetric distribution of power. This is in agreement with Harris (2004; 2006), for whom the observed form of leadership in a PLC is distributed. As asserted by Bennett, Harvey, Wise, and Woods (2003), distributed leadership is not exercised by one person over others, but is more so the property of a group or a network of persons that bring their expertise together productively. It is within groups that strive for improved achievements, notably within PLCs, that we can recognize distributed pedagogical leadership (Leithwood, Jantzi, \&
Stinbach, 1999; Leithwood et al., 2006; Spillane, Harverson, \& Diamond, 2004; Stoll \& SeashoreLouis, 2007).

These observations converge with those made by Hill (1995), who asserted that the leadership of teachers is an important factor in the implementation of a PLC. In fact, a team must be encouraged to develop a culture of team inquiry, aiming to improve pedagogical practices to respond more effectively to the needs of all students (Hopkins \& Reynolds, 2001; Smyth, Dow, Hattam, Reid, \& Shacklock, 2000). Teachers and principals will develop certain ways of thinking, reflecting, and problem solving by analyzing their data and results achieved. This process alone opens the way to leadership development on all levels, called "distributed pedagogical leadership" in various studies (Kaser, Mundry, Stiles, \& LoucksHorsley, 2006).

Having explained the theoretical concepts underlying the current research project, we must now describe the methodology used.

\section{Methodology}

This research was developed within the context of an interpretative research paradigm. For elementary French-language schools, operating as a PLC is a relatively unknown phenomena, and it appears reasonable to make use of a multicase study that will allow the researcher to acquire a deeper understanding of the context and a holistic vision of the process (Gay, Mills, \& Airasian, 2006) to explain the evolving and complex character of this real-life phenomena. Therefore, the multicase study has the advantage of capturing the complexity and depth of the social situations under review so as to better understand the interaction of the factors involved.

This research has three phases. In the first phase, from 2006 to 2008, the research team developed a grid to follow the progression of the schools as PLCs. Three to five group meetings per school were held with 138 participants from 15 elementary Frenchlanguage schools. Eight of the 15 schools are in the Toronto region $(n=62)$, five in the Southwestern region of Ontario $(n=60)$, one in Ottawa $(n=8)$, and one in the Outaouais region $(\mathrm{n}=8)$.

This sample of participants is composed of 15 principals and 123 teachers. The principals include 6 men and 9 women with an average age of 43.57 and with an average of 15.71 years of teaching experience, as shown in Table 1. 
As for teachers, 6 were men and 117 were women. On average, the teachers were 40.39 years of age. The average number of teaching experience was 12.78 years. Table 2 illustrates teachers' characteristics.

In each school, individual interviews were conducted with four to eight participants, for a total of 98 interviews. The participants were asked to give their

Table 1 - Sample of Principal Participants

\begin{tabular}{lccc}
\hline & Minimum & Maximum & Average \\
\hline Chronological Age & 35 & 56 & 43.57 \\
\hline $\begin{array}{l}\text { Years of Teaching } \\
\text { Experience }\end{array}$ & 11 & 20 & 15.71 \\
\hline
\end{tabular}

personal views on the meaning of a PLC, the topics discussed in the group meetings, and other similar subjects regarding PLCs. In summary, the agenda of

Table 2 - Sample of Teacher Participants

\begin{tabular}{lccc}
\hline & Minimum & Maximum & Average \\
\hline Chronological Age & 22 & 65 & 40.39 \\
Years of Teaching & 1 & 33 & 12.78 \\
Experience & & &
\end{tabular}

the group meetings and the individual interviews were organized along the lines of the seven indicators previously identified: the school's vision; the physical and human conditions that encourage teachers to cooperate, learn and share together; the cooperative culture of the school; the manifestation of leadership from both teachers and school administrators; the professional development of the teaching staff; the topics discussed during meetings; and the manner in which decision making takes into account concerns related to student learning. An analysis of available documentation (agendas, records of decisions made in meetings, etc.) was also performed, as well as observation sessions (three to five per school). The teachers involved were from the preschool level and grades 1 through 3. By conducting these interviews, we were able to confirm the three steps in the progression of schools using the seven indicators listed above and to establish the PLCOG from Leclerc, Moreau and Lépine (2009a).

From April 2008 to April 2009, the second phase took place. Using data collected during group interviews and private meetings from the 15 participating schools, the researchers studied the factors influencing the progression of schools as PLCs and the effect on the school principals. The results of the second phase were published in Leclerc, Moreau and Lépine (2009a).
Finally, in the third phase from April 2009 to June 2010, data relevant to the factors that influenced how six of the schools were operating as PLCs was analyzed; two schools were at the initiation stage (level $1)$, two were at the implementation stage (level 2), and two were at the integration stage (level 3). Therefore, the six cases under review cover the three stages of progression. The following paragraphs will present the participants, the data collection instruments, the progress, and the methods used for data analysis of the six schools.

\section{Participants}

The six participating French-language elementary schools are located in different regions of Ontario: three from southern Ontario, two from southwestern Ontario, and one from eastern Ontario. Using the PLCOG grid, it was determined that two schools are at the initiation stage (level 1), two are at the implementation stage (level 2), and two are at the integration stage (level 3). The 45 participants in the survey sample include 6 school principals and 39 education professionals, with 8 men and 37 women. The average age of the education professionals is 41.80 years, and the average number of years of teaching experience is 13.78 .

The teachers involved were from the preschool level and grades 1 through 3: Seven were in the preschool level; four taught grade 1; seven taught multilevel grades 1 and 2 classes; four taught grade 2; eight taught grade 3; five were responsible for specialeducation students; and four were lead teachers. In total, 17 participants came from two schools at the initiation stage, 14 from two schools at the implemen-

\begin{tabular}{lccc}
\hline Table 3 - Sample of French-Language & Teacher Participants \\
\hline & Minimum & Maximum & Average \\
\hline Chronological Age & 25 & 61 & 41.80 \\
$\begin{array}{l}\text { Years of Teaching } \\
\text { Experience }\end{array}$ & 1 & 32 & 13.78 \\
\hline
\end{tabular}

tation stage, and 14 from two schools at the integration stage.

\section{Data Collection Instruments}

The primary data collection tool for the third phase was a semidirected interview of approximately one hour with each participant focusing on explaining the factors that influence the functioning of the school as 
Table 4 - Analysis of all participants

\begin{tabular}{l|cccccc}
\hline & School 1SM & School 1SP & School 2SA & School 2SM & School 3JP & School 3T \\
\hline $\begin{array}{l}\text { Number of Partici- } \\
\text { pants }\end{array}$ & 9 & 8 & 8 & 6 & 6 & 8 \\
Chronological Age & 44.23 & 46.46 & 42.31 & 35.93 & 41.85 & 37.72 \\
$\begin{array}{l}\text { Years of Teaching } \\
\text { Experience }\end{array}$ & 16.45 & 17.84 & 13.13 & 11.70 & 7.70 & 12.03 \\
\hline
\end{tabular}

a PLC. The interview design consisted of a series of themes relevant to the research, structured along the Seidman model (1998). The design has three essential components: 1) the context of the teaching experience, 2) the details of the experience, and 3) participants' thoughts on the significance of the experience. The first component is used to establish the context of participants' experience, which is done with the first interview question. This question, suggested by Seidman, prompts participants to speak as openly as possible about their experiences, because this is the first tentative step to put in place a PLC in the school at the present moment. By having the context of the participants' experiences accessible and comprehensible, the researchers were better able to understand the significance that the participants confer to their experiences. The second component, questions two through seven, allowed us to recreate the details of the participants' experiences with the PLC. According to Seidman, these details taken in context will allow the researcher to recreate the participants' opinions in relation to their real-life experience. Finally, the interview closed with a general question pertaining to the participants' thoughts on the significance of their experiences, structured to allow participants to articulate their views of past experiences and future expectations on this topic. This last question establishes intellectual and emotional connections that informed the researchers on the consistency of participants' responses. The researchers could also observe the coherence, or lack thereof, of the responses and validate the interpretations.

Group interviews and observations during collaborative meetings allowed the researchers to finalize the data. The mixture of participants (teachers, principals, and specialists for students with learning difficulties) combined with the variety of tools available, such as observation notes, document analysis, data collected during group meetings, and individual interviews, allowed for a certain triangulation of the techniques used by corroborating the responses of teachers and their representations.

\section{Data Analysis}

The codification approach used an inductive logic model, based mainly on the researcher's analysis of the information collected, to discern interactions and concepts (Savoie-Zajc, 2000). The codification took place in two key passes: a first interpretation allowed us to synthesize and then identify emerging key categories, and then the second pass consisted of inputting the interview transcripts. Note that this approach was validated by two independent specialists.

The qualitative data was processed using the Atlas.ti software, which allowed the researchers to capture lexical units and codify the categories. During the codification procedure, the researchers separated the information obtained, that is, they identified an information element; isolated it; and categorized it along with other elements of the same type, removing its particular characteristics and context (Deslauriers, 1991). They then identified lexical units and, to the extent possible, attempted to ensure that elements do not belong to two different categories (exclusive categories). A lexical unit, also known as a "registration unit," can be a word, a group of words, a sentence, or a group of sentences that is completely meaningful by itself and that will be the basis for subsequent classification or codification (Deslauriers, 1991). The lexical unit is the smallest information element with a relevant significance for the research. The researchers grouped the comments to identify the key emerging categories. In the current study, certain lexical units would sometimes refer to different realities and, consequently, it was difficult to place them in a single category without losing information in subsequent content analysis. In these rare instances, we preferred to include the units in more than one category. A category is the common denominator to which is assigned a series of statements and represents a concep- 


\section{Figure 1}

\section{Major Factors Applicable to All Stages}

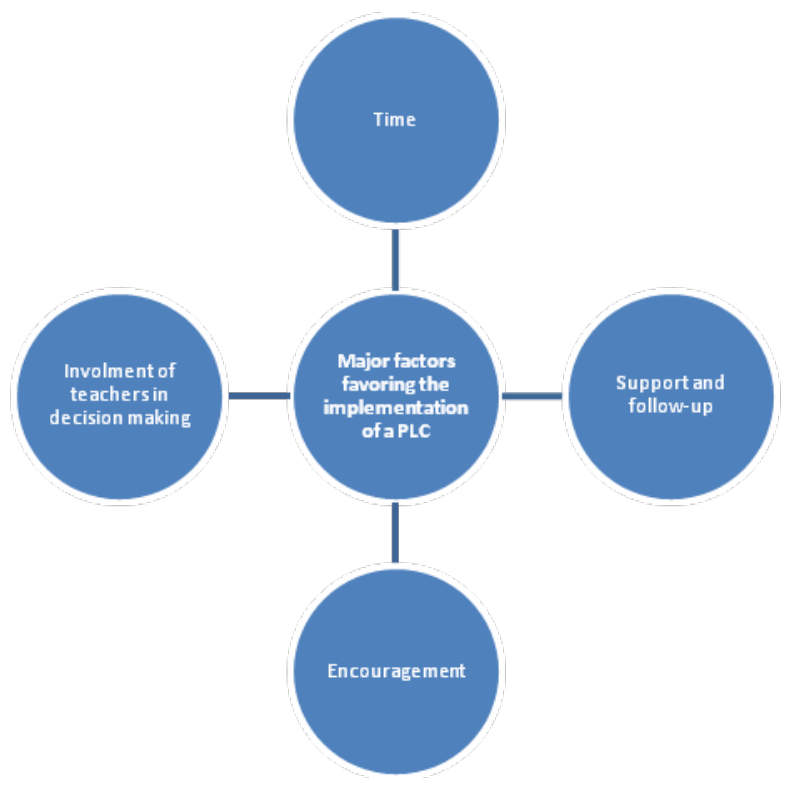

tual dimension (ibid). Categories do not exist at the beginning, but are progressively deduced as the researcher reviews the assembled material, discovers similarities within the data, and identifies recurrent themes. This analysis leads to the identification of factors that promote or detract from operating as a PLC.

\section{Results}

The purpose of this study is to identify factors that influence the functioning of a school as a PLC and to analyze the links between these factors and the school's progression. Certain circumstances seem to be winning conditions to facilitate the progression of a school as a PLC.

Initially, we will describe the factors relevant to the school's development as a professional learning community, regardless of the stage reached by the school. Subsequently, we will identify the factors that are more closely associated to a stage of progression.

\section{Factors Influencing the Progression of a School as a PLC, Regardless of the Stage}

In short, certain conditions are essential to ensure a school's progression to a PLC, regardless of its current stage of development: making time for meetings, ensuring support for teachers and a follow-up to the collaborative meetings, and recognizing success by encouraging staff and involvement of teachers in decision making.

Time

Having time set aside during school hours for collaborative meetings is a crucial organizational factor to promote the development of a PLC; this comment was repeated some 50 times by teachers and 3 times by school principals. The participants from schools at the initiation stage as well as the implementation and integration stages emphasized the importance of holding these meetings during school hours: "I would say that being liberated from the classroom is one of the keys to the success of our PLC" (2ES6). "We have monthly meetings, which helps tremendously" (352). "It's designing a timetable with meetings, not at 7:00 in the morning or 5:00 in the afternoon, but between $8: 30$ a.m. and 3:30 p.m. This is our reality, this is our school's timetable" (3S1). The participants mentioned that a half-day every month or every six weeks is desirable. The schools in the integration stage admitted that a certain number of adjustments was necessary because of the times allocated to meetings. At the very beginning of the implementation of the PLC, meetings were too short, but later the formula started bearing fruit: "A oneand-a-half-hour meeting would go by very fast and we didn't have time to discuss. We always seemed to 
be rushed for time. So, we were told that we would be given one half-day. In the last several months, each collaborative team has met one half-day per month. We can now accomplish many more things" (3JPSB). Time seems to be an obstacle in the progression of schools at the initiation stage; participants speak in a qualified fashion stating the need to have more time for meetings: "Conditions to put in place ... I would like that we could have a half-day per month" (1BS6). "It's not always easy to get together. The ideal for us is to hold many similar sessions, i.e., half-days during the school year" (1BSD). "If we had meetings, we would have to attend, we would have no choice. So, you will start to share since you have the time and you feel less stressed. So, you may as well contribute" (1BS7).

\section{Support and Follow-Up}

Support and follow-up seems to be important regardless of the stage reached by the school. The teachers need to feel that the principal is conscious of their needs in terms of resources and supply teachers and that the principal approves the actions taken: "Here, the principal provides the time and resources required for our PLC initiatives" (3JPS3). "Well, if we need resources to do our job properly, we hope that the principal will support us and purchase what we need" (1AS10). It is also the principal's task to do the follow-up to meetings: "The principal must review what the teachers have done against the anticipated work coming out of the collaborative meetings. If there is something that a teacher does not understand, it can be added to the agenda for the following collaborative meeting. And this is good for the progress of knowledge and for education" (2ES9). The requirement to ensure a follow-up to meetings is corroborated by other principals: "I am the one who assumes a liaison role when it's required" (2ESD). "She is interested and she is also very much aware what goes on in our PLC meetings, not only what goes on in the school" (2ES2). The principal of a school at the integration stage maintains that the involvement of the administration is crucial for the success of a PLC. That is why the principal keeps abreast of what has been discussed in collaborative meetings and reacts to the opinions articulated.

In contrast, a lack of support and follow-up from the principal appears to be an obstacle to the progression of the school as a PLC for schools in the initiation stage: "When I take into account the principal, I'm not sure that we have the support required to move further. I find that when we hold a PLC meeting, the principal should be there to support us; there are things that I see that haven't changed, and it's always the same issues that come back. Things should change" (1AS6).

\section{Encouragement}

Encouragement is repeated regardless of the stage reached by the school: "The principal is also very helpful in [his] encouragement" (2ES5). "The principal drives us, [he] leads, [he] points us in the right direction. And [he] also provides much encouragement if you have a new idea, a new issue, it is always very open" (2ES3). The principal substantiates the importance of underlining good proposals: "I will applaud success stories when they happen" (2ESD). Even in the integration stage, teachers appreciate the principal's encouragement: "We felt the principal was supportive, we did not feel belittled. As a result we were motivated, this year we are doing more, and next year we will do even more" (3S6). "She always draws out the positive from people. When she talks, it's never negative. She always looks for the positive aspects in a situation" (3S8).

\section{The Involvement of Teachers in Decision Mak- ing}

Teachers, regardless of the PLC stage reached by the school, recognize the importance of being involved in the decisions that the principal must take: "What I like of our principal is that she really listens to the teachers and relies on their ideas. That is really important, it's excellent!" (2ES9) The principal consults with teaching staff to understand their needs: "If the principal relies on the ideas coming from teachers, the teachers will be motivated. They have invested time, energy, emotions. They are much more apt to work harder and work longer, and to keep on doing so than if someone tells them what to do. In the latter case, you lose your motivation" (2SM1). The principal of a school in the integration stage believes requests must be evaluated against the recognized priorities: "A principal must be creative when taking decisions with the school's budget. If teachers ask for tables and we are able to justify this choice at the educational level, the principal will be able to find the resources and say yes, it's possible!" (3S3) Moreover, at the integration stage, teachers believe that the principal should not be too rigid: "Someone that is a bit too 
rigid, too imposing, I'm not sure that it would work as well" (3S4). "They give us that freedom" (3JPSA).

\section{Factors More Applicable to Certain Stages of Progression of the School as a PLC}

Certain distinctions must be made among the stages of progression. At the initiation stage, it appears crucial to ensure that team members share and accept the vision and expectations. In addition, meetings must be structured to be productive. It is vital that the principal be present and provide some guidance. At that stage, it is essential to develop a culture of collaboration that is the foundation for a genuine PLC. At the implementation stage, it seems that having a model of a more advanced PLC can promote the progression of the school as a PLC. The principal also has a crucial role to play, namely to promote inquiries and questioning by the teachers just like a research team (a culture of inquiry). Finally, at the integration stage, the characteristic factors of a school operating as a PLC are a) distributed leadership among the teachers; b) the importance attached to the monitoring of learning, allowing discussions to be refocused on the achievements of students; and c) more engaging options for the teacher development.

\section{Clearly Defined Expectations and Vision}

Schools at the initiation stage expect the principal to undertake activities that will facilitate the buy-in of teachers, which does not normally happen and which restrains the school in its progression as a PLC: "It's difficult to be in a certain place and then to bring everyone together. I believe that some changes are required. But, I am not the one that will make these changes myself, that's just not true" (1AS6). "I believe it's a lack of leadership on the part of the principal. To make sure we know exactly what the expectations are in respect of a PLC" (1BS5).

\section{Principal: Presence and Guidance During Dis- cussions}

The participation of the principal during collaborative meetings appears especially important for schools in the initiation stage, when the team has not yet acquired the skills required to lead collaborative meetings successfully: "She must be present. She must show that she embraces the concept" (1BS1). "He or she must be a leader more or less capable of stimulating good ideas from people and reaching a conclusion. Tying ideas together to reach a conclusion and to establish a consensus, a leader who is capable of making decisions on that subject" (1BS2). The school principal's presence at collaborative meetings appears

Figure 2

Factors More Applicable to Certain Stages of Progression of the School as a PLC

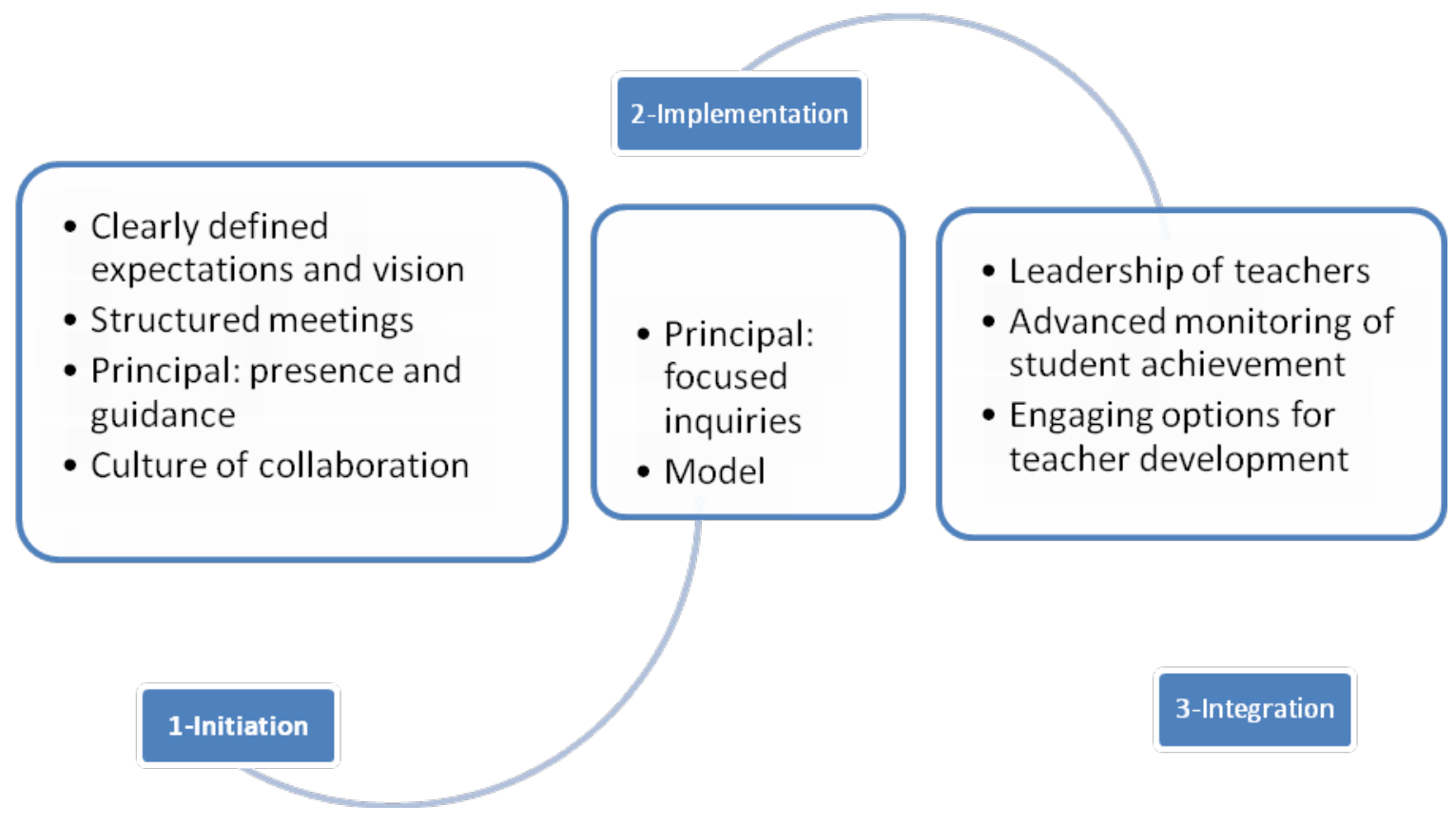


crucial to ensure that constructive discussions occur during these meetings, as corroborated by a principal from a school at the integration stage: "My role is to always remind the teachers of the reason for completing these evaluations and for which we take decisions" (3JPD).

Finally, we see that guidance of teachers is more effective in the initiation stage: "Our principal leads us. Sometimes he decides the subject matter" (1AS3). "Since becoming our principal, he will often give us some work, for example, we will work on this item for 15 minutes. For us, this is what working as a PLC means" (1AS9). The teachers seem to depend on initiatives taken by the principal: "Personally, the principal could play a more active role. Maybe initiate our collaborative meeting, you know, to start it off. Perhaps say, 'here is what I propose' "( $1 \mathrm{BS} 1$ ). At this stage, teachers appear to be in need of guidance: "Whether you like it or not, there must be a captain, there must be someone to take charge to move forward correctly. [...] If there are certain things that you need to impose, then impose them. If need be, call it a collaborative meeting, but it's a time when we must meet. Then say, 'here's the problem and here's how we will deal with it.' There has to be someone in charge of everything, otherwise ... Either someone is designated to do something or the administration does it" (1BS2). Teachers wait for the principal to show some leadership: "It has to be a real leader who can win over teachers to produce new ideas but then reach a conclusion. That is, a real leader that can make decisions on the subject" (1BS3). "Well, I think that it is the principal that must point us in the right direction. I am not the one who will say 'OK, I would like a PLC' because the others will look at me as if I'm crazy. So, I think it must come from the principal so that we can get used to the idea, before we can achieve a good PLC" (1BS6).

\section{A Culture of Collaboration}

For schools in the initiation stage to progress requires a greater openness of mind: "There needs to be open communication between teachers to facilitate the sharing of concerns and then identify where the needs are" (1BS5). Teachers working by themselves are major obstacles in schools at the initiation stage: "We each go our own way and then we close the door" (1BS2). At this stage, teachers consider meetings more of a burden than as a means of mutual assistance and mutual progress: "Sometimes, when you work as a group, there are some that are not at the same level, and then it's difficult to reach a goal when not all participants have reached the same level of experience and growth" (1AS2).

A culture of collaboration within the school is a very important aspect. We observe that in the implementation stage, teachers are very aware that they must be open to criticism from their colleagues: "To have, for teachers, the opportunity to meet and discuss deficiencies" (2ES9). "I believe that when there is a good atmosphere of collaboration within a school, this promotes an exchange of views" (2SMD). For these schools, the culture of collaboration goes beyond just sharing. There is mutual assistance and questioning: "Working as a PLC means mutual assistance and really taking the time to question ourselves as a group" (2ES3). In the implementation stage as well as in the integration stage, many of the comments emphasize that the exchange of views reveals a mind open to criticism as well as mutual respect, but this type of comment is not found in the language of participants from schools in the initiation stage.

\section{Principal: Focused Inquiries}

At the implementation stage, the role of the principal during collaborative meetings is crucial. Her guidance is achieved by introspection centered on pedagogical issues: "She gets people to question themselves and find answers. Sometimes we go off on a tangent. And then she brings us back to the issue at hand. She lets us express our thoughts, find our own answers, find our own paths" (2ES6). The principal of a school at the implementation stage attests to the need of promoting adequate questioning within the team: "I attended some of the meetings, not all. I questioned, I wanted to know why a certain student was progressing while another wasn't. I stayed on the issues and I think questioning is probably what I did the most" (2ESD).

\section{Model}

Schools in the implementation stage feel the need to have a model of a school operating as a PLC: "Personally, I would like to see the ideal PLC. I would need to see the actual operations so that I may go and understand the elements which we are lacking" (2ESD). "It has to be clearly explained, what exists and what we need to do to achieve those PLCs. If I don't get my answer here, then I must go somewhere else to find it" (2BS2). 


\section{Leadership of Teachers}

In the integration stage there is a greater commitment from teachers: they take the initiative and they undertake activities without waiting for the agreement of the administration: "My group and I, we share this philosophy: we have a need, we have a problem, we need this or that resource, then, we always go to the principal with a solution in hand. Last year, when we told the principal that we would like more time to get together than the current half-days, was it possible? We would like to have management time together or a lunch together. We had previously considered certain solutions so that the principal would know that we had considered the problem and had some suggestions" (3S4). At this stage, teachers are showing leadership that can be associated with the concept of distributed pedagogical leadership within the school (Harris, 2006): "We already meet on our own time, in the morning, from 8:00 to 8:30. When we decide we need to discuss something, I send an e-mail to the group" (3S6). In these schools at the integration stage, the principal understands that she can't make all the decisions simply because she does not master all the elements. She must delegate part of the work, part of the decision making: "The principal cannot be an expert in all areas. She must accept that at each meeting some participants will leave with different questions, some with different interpretations, and some with different work objectives. From month to month, experts are born within the school. It cannot be the school principal being an expert in everything" (3SD). The principal must not only promote the dissemination of expertise within the school but must also make use of the knowledge of teachers: "A teacher will be an expert on one topic or another for the other teachers as well as for the principal, who will find herself in a learning situation. In my case, I now recognize this. After two years as a principal, I now consult the teachers; it is not for them to come and ask permission. The principal must not be, and will not be, the pre-eminent pedagogical leader for the school" (3SD).

\section{Advanced Monitoring of Student Achievement}

Questioning seems more advanced at the integration stage and more focused on student learning: "I see my role as one where I can bring about some situations, where I can ask questions that stimulate discussions amongst the teachers concerning student learning. I can provide orientation, give sense to... But espe- cially, provide a framework. I rock the boat somewhat, otherwise matters would not move as fast" (3JPD). In schools at the integration stage, the principal ensures that constructive discussions during these meetings are based on learning data and centered on pedagogical issues: "My role is always to remind the teachers of the reason for completing these evaluations and for which we take decisions" (3JPD).

\section{Engaging Options for Teacher Development}

There are mechanisms that promote the sharing of best practices and their evaluation by peers, and they exist mainly in schools in the integration stage. In these schools, there is a dissemination of expertise within the teaching body: "More and more often, people come to ask me questions when they observe certain behavior in a student and they are not sure how to react. Previously, they would consult another teacher who had received some training, but now some people are starting to come to me. The expertise is shared" (3S2). "Some people have expertise in a certain field, others in a different field. We exchange ideas, we question together, we really learn together. I really believe that each person brings to the group what he or she knows best. We really learn by one another. So, I think that I'm really fortunate to share ideas with colleagues that have enormous knowledge from a theoretical point of view. I think our team benefits tremendously from this situation" (3S4). Depending on their specific expertise, teachers will undertake research to respond to a precise need to augment their knowledge and will subsequently share their discoveries. This is corroborated by the school principal. At the integration stage, we also use more appealing procedures to promote learning by teachers, as emphasized by the school principal who endorses the idea that teachers observe in the classroom of colleagues and exchange ideas afterwards: "I have the impression that exchanges between teachers is useful. One teacher will observe the other and afterwards they will exchange ideas and see how they can improve their classroom practices" (3JPSD).

\section{Discussion}

Certain circumstances seem to culminate in winning conditions to facilitate the progression of a school as a PLC. These conditions are categorized into four themes, as presented in the following paragraphs, and can serve as recommendations for principals who would like to see their school progress. 


\section{Create a Structure That will Counter the Isolation of Teachers}

It goes without saying that time is a crucial factor, because all participants, regardless of the stage reached by their school in its progression as a PLC, mentioned the difficulties that emerge when meetings are imposed outside of regular school hours. This is in agreement with Boyd (1992), who emphasizes the necessity of implementing a structure to counter the isolation of teachers, as well as with Hord and Sommers (2008), who hold that time is the factor that represents the greatest challenge for the implementation of PLCs. This factor certainly has an effect on school operations, as the budget for supply teachers (making time for meetings), as well as the overall organization of the course calendar (common management time) must be considered. Furthermore, the proximity of classrooms for teachers of the same grade level was stated by schools at the integration stage as helping in promoting collaboration among teachers and allowing them to share knowledge.

\section{Strive for Student Success}

Having a shared vision from which flows clear expectations (Blase $\&$ Kirby, 2010) and clearly identified priorities (Hord \& Sommers, 2008), is certainly a crucial factor for student success. In schools at the integration stage, the school's vision, goals, and objectives are shared by the entire staff. This is in line with Adajian (1996), who asserts that the expectations for student success must be clearly expressed to ensure the progression of a PLC.

Furthermore, having a structure in place to ensure effective collaborative meetings is a determining factor. Guidance is just as crucial for the school to progress from the initiation stage to the implementation stage. This guidance can be made by an education consultant or by any other person with a good understanding of the skills necessary for working as a PLC, and is perceived to be a crucial factor for the development of leadership among teachers (Harris \& Muijs, 2004).

Finally, the atmosphere of collaborative meetings is an unavoidable socio-organizational condition for success. This includes a climate of confidence among staff members, a mutual respect among colleagues, and a willingness to share (Cibulka, Coursey, \& Nakayama, 2000; Harris, 2008).

\section{Create Mechanisms That Promote Teacher Learning}

Bringing teachers to work together and learn from one another creates a certain capacity to establish sustainable changes (Harris, 2008; Leclerc et Moreau , 2010); only in this way can a school continue to improve. This can be seen in four ways:

1. The school must offer instances where teachers are encouraged to discuss pedagogical practices among themselves and conduct peer evaluations. This method is much more stimulating than simply sharing course materials and planning (Letor, 2006).

2. The adoption of a culture of inquiry based on concerns with student progress is a promising topic in the development of teacher learning. Accordingly, during collaborative meetings, it is desirable that teachers and the school principal resolve problems together concerning student learning through analysis of their data. The team must therefore act as a research team.

3. It is beneficial for teachers to observe one another in the classroom and provide feedback, which is in agreement with the views of Harris (2008), for whom the review of teacher interventions by colleagues and their feedback is an indispensable element of a PLC.

4. The dissemination of expertise among teachers from different schools is an interesting option for schools at the initiation and implementation stages, as it allows teachers to visualize the new concept of schools operating as a PLC and to internalize this method of functioning. It can also promote the sharing of expertise among schools in regard to proven educational strategies.

\section{Redistribution of Leadership Within Schools}

Hill (1995) asserts that the leadership of teachers is an important factor in the implementation of a PLC. Studies of effective schools have recognized the need to rethink the roles of school principals and of teachers (Leithwood \& Jantzi, 2000; Devos, Van den Brock, \& Vanderheyden, 1998). Today, researchers recognize that leadership is a dynamic process involving many individuals, and that it is also a matter of shared management that confers more responsibilities to members of the team, rather than the school principal (Cibulka, Coursey, \& Nakayama, 2000). By it- 
self, this practice opens the way to the development of leadership at all levels, which Leithwood et al (2006) describe as distributed pedagogical leadership.

In essence, the results of our current study generally support the conclusions of other researchers examining the need to support teachers to facilitate the functioning of schools as a PLC (Hopkins \& Reynolds, 2001; Hord \& Sommers, 2008; Leclerc, Moreau, \& Lépine, 2009a). The results of our study agree with those reached by Gordon (2004) and Sparks (2002), which highlight the importance for school principals to possess the skills required to progress their school as a PLC and which state that training is essential for school principals so they are able to better understand the concept and dynamics of a PLC.

This study has allowed us to better understand the factors that come in to play when fostering the progression of schools as PLCs. In fact, many factors appear essential, especially at the initiation and implementation stages. It becomes apparent that schools operating in a more traditional hierarchy must develop a form of distributed pedagogical leadership, as it is required to reach the integration stage. Similarly, traditional structures that define the role of the incumbent and promote a partition between classes are obstacles to fluid leadership within the school, and the dissemination of learning between colleagues, which are necessary conditions for working as a PLC. To progress their school as a PLC, principals must exercise a leadership that corresponds well with a learning organization: for example, articulating a vision, offering support to the team, developing a culture of questioning and a critical mind, promoting teacher learning and the dissemination of expertise, developing precise expectations, and promoting a culture of collaboration.

\section{References}

Adajian, L. B. (1996, April). Professional communities: Teachers supporting teachers. Mathematics Teachers, 89(4). pp. 321-324.

Bennett, N., Harvey, J. A., Wise, C., \& Woods, P. A. (2003). Distributed leadership: A desk study. Retrieved from http://www.nationalcollege.org.uk/ docinfo?id=17151\&filename=distributedleadership-full-report.pdf
Blase, J., et Kirby, P. C. (2010). Des stratégies pour une direction scolaire efficace: Motiver et inspirer les enseignants. Traduction et adaptation de Bringing Out the Best in Teachers de Joseph Blase et Peggy C. Kirby @ 2009 . Corwin Press Inc., A Sage Publications Company (United States, London and New Delhi)

Boyd, V. (1992). School context: Bridge or barrier to school change? Austin, TX: Southwest Educational Development Laboratory.

Busher, H. (2006). Understanding educational leadership: People, power and culture. Berkshire, England: Open University Press.

Cate, J. M., Vaughn, C., \& O'Hair, M. J. (2006). A 17year case study of an elementary school's journey: From traditional school to learning community to democratic school community. Journal of School Leadership, 16(1). pp. 86-111.

Cibulka, J., Coursey, S., \& Nakayama, M. (2000). Schools as learning organizations: A review of the literature. The creation of high-performance schools through organizational and individual learning. Washington, DC: National Partnership for Excellence and Accountability in Teaching.

Cuban, L. (1992, January/February). Managing dilemmas while building professional communities. Educational Researcher, 21(1). pp. 4-11.

Deslauriers, J. P. (1991). Recherche qualitative: Guide pratique. Montréal, Canada: Chenelière/McGrawHill.

Devos, G., Van den Brock, H., \& Vanderheyden, K. (1998). The concept and practice of a schoolbased management contest: Integration of leadership development and organizational learning, Educational Administration Quarterly, 34(1). pp. 700-717.

Dibbon, D. (2001). Diagnosing the Extent of Organizational Learning in Schools. Washington, DC: American Educational Research Association.

DuFour, R., \& Eaker, R. (2004). Communautés d'apprentissage professionnelles: Méthodes d'amélioration du rendement scolaire. Bloomington, IN: National Education Service, and Alexandria, VA: ASCD.

Gay, L. R., Mills, G. E., \& Airasian, P. (2006). Educational research: Competencies for analysis and applications (8th ed.). Upper Saddle River, NJ: PearsonMerrill Prentice Hall.

Gordon, S. P. (2004). Professional development for school improvement: Empowering learning communities. Boston, MA: Allyn and Bacon. 
Harris, A. (2004). Distributed leadership in schools: Leading or misleading? Educational Management and Administration, 32(1). pp. 11-24.

Harris, A. (2006). Opening up the 'black box' of leadership practice: Taking a distributed leadership perspective. International Studies in Educational Administration, 34(2). pp. 37-45.

Harris, A. (2008). Distributed school leadership: Developing tomorrow's leaders. London, England: Routledge.

Harris, A., \& Muijs, D. (2004). Improving schools through teacher leadership. London, England: Open University Press.

Hill, D. (1995). The strong department: Building the department as learning community. In L. S. Siskin $\& \mathrm{~J}$. W. Little (Eds.), The subjects in question: Departmental organization and the high school. New York, NY: Teachers College Press. pp. 123-140.

Hopkins, D., \& Reynolds, D. (2001). The past, present, and future of school improvement: Towards the third age. British Educational Research Journal, 27(4). pp. 459-475.

Hord, S. M. (1997). Professional learning communities: Communities of continuous inquiry and improvement. Austin, TX: Southwest Educational Development Laboratory.

Hord, S. M., \& Sommers, W. (2008). Leading professional learning communities: Voices from research and practice. Thousand Oaks, CA: Corwin Press.

Huffman, J. B. (2003). The role of shared values and vision in creating professional learning communities. NASSP Bulletin, 87(637). pp. 21-34.

Huffman, J. B., \& Hipp, K. K. (2003). Professional learning community organizer. In J. B. Huffman \& K. K. Hipp (Eds.). Professional learning communities: Initiation to implementation. Lanham, MD: Scarecrow Press.

Kaser, J., Mundry, S., Stiles, K. E., \& Loucks-Horsley, S. (2006). Leading every day: 124 actions for effective leaders. Thousand Oaks, CA: Corwin Press.

Leclerc, M., et Moreau, A. C. (2010). La diffusion de l'expertise au sein de la communauté d'apprentissage professionnelle comme levier à la réussite des élèves. Le point en administration scolaire, 12(4). pp. 22-28.

Leclerc, M., \& Moreau, A. C. (2009). La réussite des élèves en lecture au cour du travail collaboratif. Le journal de l'immersion, 31(1). pp. 24-31.
Leclerc, M., Moreau, A. C., \& Leclerc-Morin, M. (2007). Les facteurs favorables à l'implantation d'une communauté d'apprentissage professionnelle dans une école franco-ontarienne. La Revue du Nouvel-Ontario, 32. pp. 51-70.

Leclerc, M., Moreau, A. C., \& Lépine, M. (2009a, September). Professional Learning Communities: What Schools are Saying of the Ways used to Improve Their Performance. European Conference on Educational Research (ECER), Vienne, Autriche.

Leclerc, M., Moreau, A. C., \& Lépine, M. (2009b, July). Using Professional Learning Communities to Improve Student Learning in Reading: Better understanding the Stages of Development. Conference européenne sur la lecture (ERA), Braga, Portugal.

Leithwood, K., Harris, A., \& Hopkins, D. (2008). Seven strong claims about successful school leadership. School Leadership \& Management, 28(1). pp. 27-42.

Leithwood, K., \& Jantzi, D. (2000). The effects of different sources of leadership on student engagement in school. In K. Riley \& K. Louis (Eds). Leadership for change and school reform. London, England: Routledge. pp. 50-66.

Leithwood, K., Jantzi, D., \& Stinbach, R. (1999). Changing leadership for changing times. Philadelphia, PA: Open University Press.

Leithwood, K., Macsall, B., Strauss, T., Sacks, R., Memon, N., \& Yaskina, G. (2006). Distributing leadership to make schools smarter. Ontario, Canada: Council of Canada.

Leonard, L. \& Leonard, P. (2003). The continuing trouble with collaboration: Teachers talk. Current Issues in Education, 6(1). Retrieved from http://cie.asu.edu/volume6/number15

Letor, C. (2006). L'établissement scolaire, lieu d'apprentissage organisationnel: Analyse de quelques conditions socio-organisationnelles et socioprofessionnelles. Mons, Belgium: FNRS

Lieberman, A. (1999). Community means more than teamwork. Journal of Staff Development, 20(2). pp. 46-48.

Louis, K. S. (2006). Changing the culture of schools: Professional community, organizational learning, and trust. Journal of School Leadership, 16(5). pp. 477-489.

McLaughlin, M. W. (1992). How district communities do and do not foster teacher pride. Educational Leadership, 50(1). pp. 33-35. 
Miller, L. (2005). Communautés d'apprentissage professionnelles: Un modèle d'enseignement en équipe. Retrieved from http://www.oct.ca/publications/pour_parler_profes sion/juin_2005/plc.asp

Roy, P., \& Hord, S. M. (2006). It's everywhere, but what is it? Professional learning communities. Journal of School Leadership, 16(5). pp. 490-501.

Savoie-Zajc, L. (2000). La recherche qualitative/ interprétative en éducation. In T. Karsenti \& L. Savoie-Zajc (Eds.). Introduction à la recherche en education. Sherbrooke: CRP. pp. 171-198.

Schussler, D. L. (2003). Schools as Learning Communities: Unpacking the Concept. Journal of School Leadership, 13. pp. 498-528.

Seidman, I. (1998). Interviewing as qualitative research: A quide for researchers in educational and social sciences. New York, NY: Teacher College Press.

Sergiovanni, T. J. (2001). Leadership: What's in it for schools? London, England: Routledge Falmer.
Smyth, J., Dow, A., Hattam, R., Reid, A., \& Shacklock, G. (2000). Teachers' work in a globalising economy. London, England: Falmer Press.

Sparks, D. (2002). Designing powerful professional development for teachers and principals. Oxford, $\mathrm{OH}$ : National Staff Development Council.

Spillane, J. P., Harverson, R., \& Diamond, J. (2004). Towards a theory of leadership practice: A distributed perspective. Journal of Curriculum Studies, 36(1). pp. 3-34.

Stoll, L., \& Seashore-Louis, K. (2007). Professional learning communities. New York, NY: Open University Press.

Stoll, L., \& Temperley, J. (2009). Creative leadership: A challenge of our times. School Leadership \& Management, 29(1). pp. 65-78.

Wenger, E. (1998). Communities of practice: Learning as a social system. The Systems Thinker, 9(5), Retrieved from http://www.ewenger.com/pub/pub_systems_think er_wrd.doc

IJEPL is a joint publication of the Association for Supervision and Curriculum Development, the Faculty of Education at Simon Fraser University, and the College of Education and Human Development at George Mason University. By virtue of their appearance in this open access journal, articles are free to use, with proper attribution, in educational and other noncommercial settings 90 days after initial publication. Copyright for articles published in IJEPL is retained by the authors. More information is available on the IJEPL Web site: http://www.ijepl.org 